\title{
Study on Total Phenolic Content (TPC), Total flavonoid Content (TFC) and Antioxidant Activities of Urtica dioica of Nepalese Origin
}

\author{
Bishan Datt Bhatt and Gagan Chandra Parajuli* \\ Department of Chemistry, Tri-Chandra Multiple Campus, Tribhuvan University, Nepal. \\ E-mail: gagancp3@gmail.com
}

\begin{abstract}
Urtica dioica, commonly known as "Sisnu" is Nepali language, has been used traditionally used in Nepal for a long time in various medical and other purposes. Hexane, chloroform, ethyl acetate and methanol extracts of Urtica dioica of Nepalese origin were extracted successively by using Soxhlet extraction method and screened for the presence of different classes of phytochemicals. The phytochemical screening test revealed the presence of phenolic, flavonoid and reducing sugars in hexane, chloroform, ethyl acetate and methanol extracts of Urtica dioica. In Hexane, chloroform, ethyl acetate and methanol extracts of Urtica dioica, total phenolic and total flavonoid content were estimated and free radical scavenging activity of was determined. Total phenolic content (TPC) was measured spectrophotometrically by using Folin-Ciocalteu reagent, total flavonoid content (TFC) by using aluminum chloride method. Gallic acid was used as the standard for the calibration of phenolics and catechin for flavonoids. The highest amount of TPC was found in methanol extract $(74.3489 \pm 1.7207 \mathrm{mg}$ GAE/g) and highest amount of TFC was found also in methanol extract $(49.6742 \pm 1.7799 \mathrm{mg} C E / \mathrm{g})$. Methanol extract showed better antioxidant property $\left(I C_{50}=85.3825 \mu \mathrm{g} / \mathrm{mL}\right)$ than other extracts.
\end{abstract}

Keywords: Urtica dioica, Nettle, Phenolic compounds, Flavonoid, Antioxidant.

\section{Introduction:}

Natural products are those substances or chemicals constituents which are obtained from different living organism ${ }^{1}$. These compounds are currently used for commercial purpose in medicine, cosmetics application and food products $^{2}$. The research in the natural products consists of the isolation, their structure elucidation and exploration of chemistry, synthesis, biosynthesis, uses and biological screening to see the pharmaceutically important activities. This research led to the discovery of the new $\mathrm{drug}^{3}$.

According to World Health Organization (WHO), 75\% people still rely on plant-based traditional medicines for the primary health treatment. ${ }^{4}$ The medicinal plants serves as a common link between the traditional and medical science as they are the main source of medicaments. The development of noble drugs is primarily through the extraction of biologically active compounds from the plants, animals or microorganisms, which were identified through medicinal use or a variety of bioactivity screening programs ${ }^{5}$.

Urtica dioica belongs to the family Urticaceae. It is a perennial herb commonly known as 'Stinging Nettle' and known as 'Sisnu' in Nepali. It is broadly distributed all through the mild and tropical regions around the world. Urtica Dioica erect perennial, $50-300 \mathrm{~cm}$ tall with 4-sided steams, armed with

* Corresponding author 
stinging hairs and opposite leaves. Urtica Dioica has many hollow stinging hairs called trichomes on its leaves and stems, which act like hypodermic needles that inject histamine and other chemicals that produce the stinging sensation when contacted by humans and other animals ${ }^{6,7,8}$.

It is widely used by the traditional medicine practitioners to cure various diseases such as Haematuria, Nephritis, Jaundice, Prostrate cancer, liver inflammation, Sexual disorder, Joints pain Arthritis, Digestion, Menorrhagia, Rheumatism, Blood purifier, Emmenagogue, Diuretic, Nasal and Menstrual haemorrhage, Eczema, anaemia, diarrhea etc. The plant contains different classes of medical importance including phytosterols, saponins, flavonoids, tannins, sterols, fatty acids, cartenoids, proteins, chlorophylls, proteins, amino acids and vitamins ${ }^{9,10,11}$.

Many studies were performed in total phenolic content (TPC), total flavonoid content (TPC) and antioxidant property of Urtica dioica extract in different origin ${ }^{2,10-18}$. To the best of our knowledge, no work has been done in comparising these properties in different extract of Urtica dioica of Nepalese origin. The present study mainly focuses on studying TPC, TFC, antioxidant property and their comparisons and relation in hexane, chloroform, ethyl acetate and methanol extracts of Urtica dioica of Nepalese origin.

\section{Experimental Methods}

The plant materials were collected from Arghakhanchi District, Nepal on September 2017 at an altitude approx. 1005 meter. The leaves of the plants were collected, shade dried, grinded and used for the extraction purpose. The dried and powdered plant material $(80 \mathrm{~g})$ was extracted successively with hexane, chloroform, ethyl acetate and methanol by Soxhlet extraction method. The filtrate was concentrated under Rotary evaporator at reduced pressure to obtain solid or semisolid extract. Then phytochemical screening test was carried out ${ }^{19}$.

\section{Total phenolic content}

The total phenolic content in plant extracts was estimated by using phenol reagent (Folin-Ciocalteu) based on colorimetric method involving oxidation-reduction. ${ }^{20}$ Gallic acid stock solution was prepared by dissolving $10 \mathrm{mg}$ of gallic acid in $10 \mathrm{~mL}$ of methanol $(1 \mathrm{mg} / \mathrm{mL} / 1000 \mathrm{ppm})$. Various concentrations of gallic acid such as $10,25,50,75$ and $100 \mu \mathrm{g} / \mathrm{mL}(\mathrm{ppm})$ were prepared. An aliquot of $1 \mathrm{~mL}$ gallic acid of each concentration in methanol was poured to $15 \mathrm{~mL}$ test tube. To that $5 \mathrm{~mL}$ of Folin-Ciocalteu reagent $(10 \%)$ and $4 \mathrm{~mL}$ of $7 \% \mathrm{Na}_{2} \mathrm{CO}_{3}$ were added to get total of $10 \mathrm{~mL}$. the blue colored mixture was shaken well and incubated for 30 minutes at $40{ }^{\circ} \mathrm{C}$ in water bath. Then the absorbance was measured at $760 \mathrm{~nm}$ against the blank containing all reagents except gallic acid. The average absorbance values obtained at different concentrations of gallic acid were used to plot the calibration curve.

The stock solutions of all extracts (hexane, chloroform, ethyl acetate and methanol) were prepared by dissolving $50 \mathrm{mg}$ in $50 \mathrm{~mL}(1 \mathrm{mg} / \mathrm{mL})$ of methanol. Serial dilutions were carried out to get concentration of $0.125,0.25,0.5$ and $1.0 \mathrm{mg} / \mathrm{mL}(125,250,500$ and $1000 \mathrm{ppm}$ respectively). To these diluted solutions, FCR and $\mathrm{Na}_{2} \mathrm{CO}_{3}$ were added and incubated for 30 minutes as in the case of gallic acid and absorbance was measured at $760 \mathrm{~nm}$ against the blank for each concentration.

The total phenolic was calculated in all the extracts separately using the formula below,

$$
C=\frac{c V}{m}
$$

Where, 
$\mathrm{C}=$ Total content of phenolic compound in $\mathrm{mg} / \mathrm{g}$, in gallic acid equivalent (GAE)

$\mathrm{c}=$ Concentration of gallic acid established from the calibration curve in $\mathrm{mg} / \mathrm{mL}$

$\mathrm{V}=$ Volume of extract in $\mathrm{mL}$

$\mathrm{m}=$ Weight of plant extract

Data were recorded as a mean of three determinations of absorbance for each concentration, from which correlation coefficient $\left(\mathrm{R}^{2}\right)$ value was calculated. The regression equation is given below.

$$
\mathrm{Y}=\mathrm{mx}+\mathrm{c}
$$

Where,

$\mathrm{Y}=$ Absorbance of extract

$\mathrm{m}=$ Slope from calibration curve

$\mathrm{x}=$ Concentration of extract

$\mathrm{c}=$ Intercept

Using this regression equation, concentrations of extracts was calculates. Thus with the calculated value of concentration of each extract, the phenolic content was calculated by the equation.

\section{Total flavonoid content}

he total flavonoid content in plant extracts was estimated by using aluminium chloride colorimetric assay. ${ }^{21}( \pm)$-Catechin stock solution was prepared by dissolving $10 \mathrm{mg}$ of $( \pm)$-Catechin in $10 \mathrm{~mL}$ of methanol $(1 \mathrm{mg} / \mathrm{mL} / 1000 \mathrm{ppm})$. Various concentrations of ( \pm )-Catechin such as 10, 25, 50, 75 and 100 $\mu \mathrm{g} / \mathrm{mL}$ (ppm) were prepared. An aliquot of $1 \mathrm{~mL}( \pm$ )-Catechin of each concentration in methanol was poured to $15 \mathrm{~mL}$ test tube containing $4 \mathrm{~mL}$ of double distilled water. At the zero time, $0.3 \mathrm{~mL}$ of $5 \%$ $\mathrm{NaNO}_{2}$ was added to the test tube. After 5 minutes, $0.3 \mathrm{~mL}$ of $10 \% \mathrm{AlCl}_{3}$ was added to the test tube. At 6 minutes, $2 \mathrm{~mL}$ of $1 \mathrm{M} \mathrm{NaOH}$ was added to the mixture. Immediately, the total volume of the was made up to $10 \mathrm{~mL}$ by addition of $2.4 \mathrm{~mL}$ double distilled water and mixed thoroughly. Absorbance of the pink color mixture was determined at $510 \mathrm{~nm}$ against the blank containing all reagents except catechin. The average absorbance values obtained at different concentrations of $( \pm)$-Catechin were used to plot the calibration curve.

The stock solutions of all extracts (hexane, chloroform, ethyl acetate and methanol) were prepared by dissolving $50 \mathrm{mg}$ in $50 \mathrm{~mL}(1 \mathrm{mg} / \mathrm{mL})$ of methanol. Serial dilutions were carried out to get concentration of $0.125,0.25,0.5$ and $1.0 \mathrm{mg} / \mathrm{mL}(125,250,500$ and $1000 \mathrm{ppm}$ respectively). Following the procedure described above, absorbance for each concentration of extract was recorded. Then total flavonoid content was calculated using above formula.

\section{Determination of antioxidant activity using DPPH radical scavenging assay}

DPPH radical scavenging activity was assessed for the determination of antioxidant power of any medical plant. ${ }^{22}$ The free radical scavenging capacity of hexane, chloroform, ethyl acetate and methanol extracts of Urtica dioica was carried out. DPPH solution $(0.1 \mathrm{mM})$ was prepared by dissolving $39 \mathrm{mg}$ of $\mathrm{DPPH}$ in $1000 \mathrm{~mL}$ methanol and stirred and kept overnight at $4{ }^{\circ} \mathrm{C}$. Thus prepared purple color DPPH free radical solution was stored at $-20^{\circ} \mathrm{C}$ for further use. The different concentrations $5,10,15$ and 20 $\mu \mathrm{g} / \mathrm{mL}$ (ppm) of each extracts (hexane, chloroform, ethyl acetate and methanol) were prepared by the serial dilution of the stock solution of respective extracts. To each $0.5 \mathrm{~mL}$ of extract solution, $2.5 \mathrm{~mL}$ of $0.1 \mathrm{mM}$ methanolic DPPH solution was added. A control was prepared by mixing $0.5 \mathrm{~mL}$ distilled water and $2.5 \mathrm{~mL} 0.1 \mathrm{mM}$ methanolic DPPH solution. These samples were well shaken and kept in dark for 30 $\mathrm{min}$ at room temperature. The absorbance was measured at $517 \mathrm{~nm}$ against the blank solution consisting 
$2.5 \mathrm{~mL} \mathrm{MeOH}$ and $0.5 \mathrm{~mL}$ distilled water. The radical scavenging activity was expressed as the radical scavenging percentage using the following equation.

$\%$ scavenging $=\left[\frac{A c-A s}{A c}\right] \times 100$

Where,

$\mathrm{Ac}=$ Absorbance of control

As $=$ Absorbance of sample solution

\section{Results and Discussion}

The phytochemical screening of the different extracts of Urtica dioica indicated the presence of major phytochemical constituents like flavonoids, polyphenols, reducing sugars etc.

Table 1: Total phenolic content and total flavonoid content in different extracts

\begin{tabular}{|c|l|c|c|}
\hline S.N. & Extract & TPC $(\mathbf{m g}$ GAE/g) & TFC (mg CE/g) \\
\hline 1 & Hexane extract & $13.7788 \pm 1.4097$ & $12.0227 \pm 2.0489$ \\
\hline 2 & Chloroform extract & $16.9820 \pm 1.3782$ & $13.0682 \pm 1.5291$ \\
\hline 3 & Ethyl acetate extract & $47.7824 \pm 2.3011$ & $27.6061 \pm 1.6213$ \\
\hline 4 & Methanol extract & $74.3489 \pm 1.7207$ & $49.6742 \pm 1.7799$ \\
\hline
\end{tabular}

Total phenolic content and flavonoid content in methanol extract was found to be highest and in hexane extract was found to be lowest.

Percentage of inhibition of DPPH free radical by methanol extract Urtica dioica was found to be nearer than other extracts to ascorbic acid which was taken as standard. The DPPH assay is based on the capability of an antioxidant compound or phytoconstituents to donate a hydrogen radical or an electron to stable DPPH radical having deep violet color. When it gets either hydrogen radical or an electron in the presence of antioxidant agent (free radical scavenger), DPPH radicals get reduced to corresponding hydrazine, DPPH-H form and the solution gets decolorized from its initial deep violet to light yellow color.

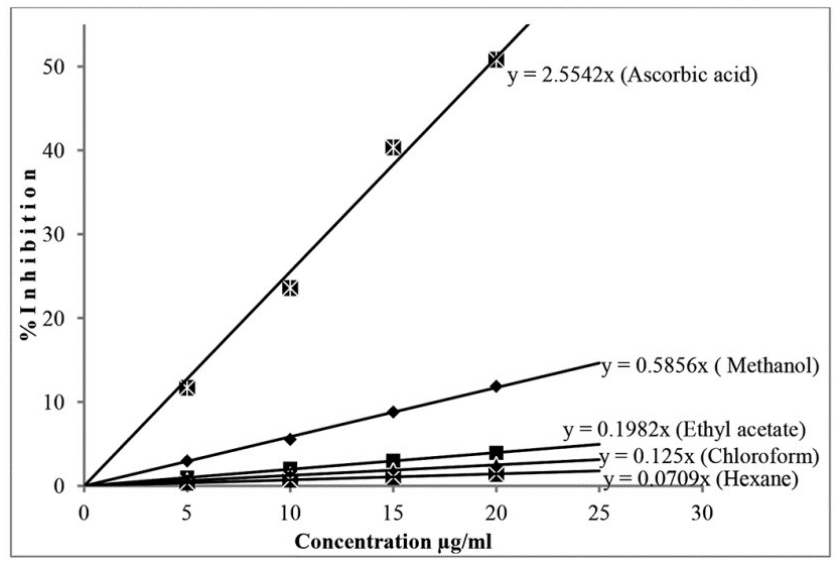

Figure 1: Free radical scavenging percentage of different extracts and ascorbic acid.

$-71-$ 
J. Nepal Chem. Soc., Vol. 36, 2017

Table 2: Antioxidant activities of Urtica dioica extracts

\begin{tabular}{|c|l|c|}
\hline SN & Extract & $\mathbf{I C}_{\mathbf{5 0}}(\boldsymbol{\mu g} / \mathbf{m L})$ \\
\hline 1 & Hexane extract & 705.2186 \\
\hline 2 & Chloroform extract & 400.0000 \\
\hline 3 & Ethyl acetate extract & 252.2704 \\
\hline 4 & Methanol extract & 85.3825 \\
\hline 5 & Standard Ascorbic acid & 19.5756 \\
\hline
\end{tabular}

\section{Correlation between total phenolic content (TPC) and antioxidant activity}

Quantitative analysis was also used for investigation the correlation between antioxidant activities and total phenolic content and total flavonoid content in different extracts of Urtica dioica. ${ }^{23}$ As the $1 / \mathrm{IC}_{50}$ (not $\mathrm{IC}_{50}$ ) value showed parallelism with antioxidant activity, therefore it was calculated and used for evaluating antioxidant activity. Plot between $1 / \mathrm{IC}_{50}$ value and total phenolic content and flavonoid content is shown in figure.

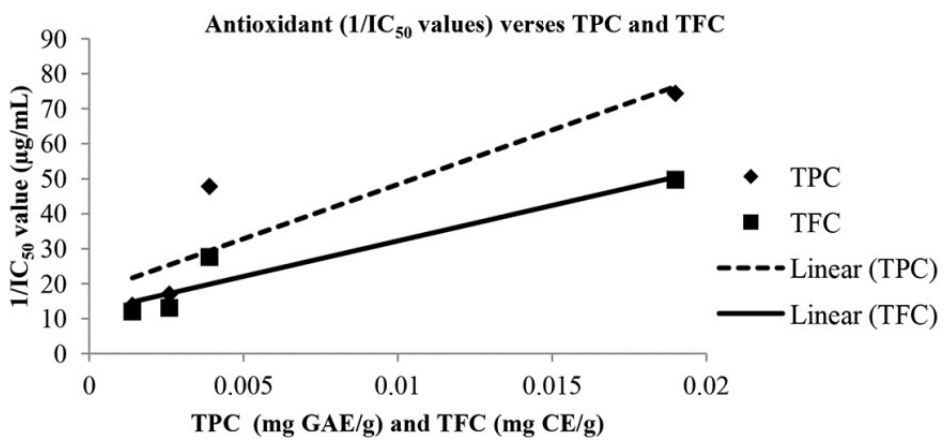

Figure 2: Plot between antioxidant activity versus total phenolic content and total flavanoid content.

A direct correlation between antioxidant activity ( ie $1 / \mathrm{IC}_{50}$ values) and total phenolic content of sample extracts was demonstrated by linear regression analysis. These results suggest that the phenolic compounds and flavonoid compounds contributed to free DPPH radical scavenging of the extracts.

\section{Conclusion}

Urtica dioica collected from Arghakhanchi district of Lumbini zone, Nepal was successively extracted with hexane, chloroform, ethyl acetate and methanol. The phytochemical screening of the different extracts of Urtica dioica indicated the presence of major phytochemical constituents like flavonoids, polyphenols, reducing sugars etc. The highest total phenolic content and flavonoid content was found in methanolic extracts as $74.3489 \pm 1.7207 \mathrm{mg} \mathrm{GAE} / \mathrm{g}$ and $49.6742 \pm 1.7799 \mathrm{mg} \mathrm{CE} / \mathrm{g}$. The methanol extract showed better antioxidant activity with $\mathrm{IC}_{50}$ value $85.3825 \mu \mathrm{g} / \mathrm{mL}$.

The overall results of this investigation indicated that plant Urtica dioica which is commonly used in food and traditional medicine for various aliment could be the source of bioactive compounds. These plants could be use as a valuable functional food ingredient or a source for nutraceutical products in future which may have possible beneficial implications in human health such as in the treatment and prevention 
of cancer, cardiovascular disease, diabetes, and other pathologies. Also, the plant possesses antioxidant property and we can say that the plant might be helpful in the preventing or slowing the progress of various oxidative stress-induced diseases.

\section{Acknowledgements}

The author would like to express sincere gratitude to Department of Chemistry, Trichandra Campus, Tribhuvan University, Nepal.

\section{References}

1. J. R. Hanson, "Natural Products; The Secondary Metabolites" The Royal Society of Chemistry, Cambridge, 2003, 1.

2. S. A. Bouchra, H. Akram, B. Houssein, R. Hassan, E. B. Ali and A. Houssein, J. Mutidisciplinary Eng. Sci. Tech., 2015, 2, 2753.

3. K. T. Farrell, "Spices, Condiments and Seasonings," C.T Westport, AVI Publishing Company, 1985, 17.

4. $\quad$ Sarker, "Natural Products Isolation", Humana Press, Totowa, New Jersey, 2006, 1.

5. S. Bhattarai, R. P. Chaudhary, R. S. L. Taylor and S.K. Ghimire, Nepal J. Sci. Tech., 2009, 10, 83.

6. L. S. Habibi, K. Amini, P. Moradi and K. Asaadi, Iran. J. Plant Physiol., 2001, 2(1), 339.

7. B. C. Joshi, M. Mukhija and A. N. Kaila, Int. J. Green Pharm., 2014, 201.

8. H. J. Al-Tameme, M. Y. Hadi and I. H. Hameed, J. Pharmacongnosy Phytother., 2015, 7(10), 238.

9. $\quad$ M. I. Aksu and M. Kaya, Food Control, 2004, 15, 591.

10. M. A. G. Maobe, E. Gatebe, L. Gitu and H. Rotich, Eur. J. Appl. Sci, 2013, 5(1), 1.

11. K.K. Ghaima, N. M. Hashim and S. A. Ali, J. Appl. Pharm. Sci., 2013, 3(5), 096.

12. M. C. Amir, I. Darah, F. S. Shaida and M. Leila, Int. J. Trop. Biol. Conserv., 2012, 60(4), 1567.

13. Z. Z. Kukuric, L. N. Topalic-Trivunovic, B. M. Kukavica, S. B. Matos, S. S. Pavicic, M. M. Boroja and A. V. Savic, BIBLID, 2012, 43, 257.

14. K. M. Sharma, V. Murugamani, A. Rajkumari, P. M. Singh, D. Awasthi and R. S. Yadhav, Pharm. Crops, 2012, 3, 38.

15. S. A. Dar, F. A. Ganai, A. R. Yousuf, M. H. Balkhi, T. M. Bhat and F. A. Bhat, Afr. J. Microbiol. Res., 2012, 27, 6893.

16. I. Gulcin, O. I. Kufrevioglu, M. Oktay and M. E. Buyukokuroglu, J. Ethnopharmacol., 2004, 90, 205.

17. R. Kraus, G. Spiteller, Phytochemistry, 1990, 29, 1653.

18. B. C. Joshi, M. Mukhija and S. Semwal, J. Appl. Pharm., 2015, 7, 120.

19. J. B. Harbone, "Phytochemical Methods," Chapman and Hall Ltd. London, 1973, 49.

20. A. Waterhouse, R. E. Ed Wrolstd, "Current protocols in food analytical chemistry", 2012, Units I1.1.1-I1.1.8.

21. J. Zhishen, T. Mengcheng and W. Jianming, Food Chem., 1999, 64, 555.

22. W. B. Williams, M. E. Cuvelier and C. Berset, Lebensm-Wiss. Technologie, 1995, 28, 25.

23. X. Li, X. Wu and L. Huang, Molecules, 2009, 14, 5349. 